\title{
Guidelines for Facilitating a Patient Empowerment Program
}

\author{
MARILYNN S. ARNOLD, MS, RD, CDE; PATRICIA M. BUTLER, PhD, RN, CDE; \\ ROBERT M. ANDERSON, EdD; MARTHA M. FUNNELL, MS, RN, CDE; CATHERINE FESTE, BS
}

The traditional medical treatment model often ignores the emotional, spiritual, social, and cognitive aspects of living with a chronic disease such as diabetes. Empowerment programs address these psychosocial areas by helping individuals develop skills and self-awareness in goal setting, problem solving, stress management, coping, social support, and motivation. Although many diabetes educators have been taught to use an empowerment curriculum to facilitate self-management, there is minimal research concerning the actual process of providing such programs to patients. We evaluated an empowerment curriculum (Empowerment: A Personal Path to Self-Care) with a diverse group of individuals with diabetes to determine the key elements of planning and implementing a successful diabetes patient empowerment program.
Empowerment is proposed as an appropriate philosophical and educational approach to diabetes care. ${ }^{1}$ This approach is based on several assumptions: most of diabetes care is provided by the person with the disease; diabetes affects the emotional, spiritual, social, physical, and cognitive aspects of a person's life; people with diabetes experience both the burdens and benefits of their diabetes and self-care choices; and patients need information about both diabetes and themselves to make informed choices. With the traditional medical model, treatment goals and plans often ignore the emotional, spiritual, social, and cognitive aspects of living with a chronic disease such as diabetes. Creating opportunities for patients to address the psychosocial issues of living with diabetes requires a more comprehensive and personcentered approach than is usually offered by the traditional medical model. A variety of materials and workshops are available to help resource educators use the empowerment approach in diabetes education. ${ }^{1-8}$

The empowerment program discussed in this paper, Empowerment: A Personal Path to Self-Care. ${ }^{9}$ was developed by one of the authors (CF). This group education program does not focus on blood glucose management or the provision of information about diabetes. Instead, the program helps participants develop skills and self-awareness in goal setting, problem solving, stress management, coping, social support, and motivation. Although at least 1500 diabetes educators have been taught to use the patient empowerment curriculum, there is little published information describing their experience of offering the program to their patients.

The Michigan Diabetes Research and Training Center evaluated the Empowerment: A Personal Path to Self-Care curriculum with five diverse groups of people who have diabetes. Participation in the course was found to be effective in improving self-efficacy and reducing glycated hemoglobin. ${ }^{10}$ Patients' individual comments reflect a variety of

From the Michigan Diabetes Research and Training Center (Ms Arnold and Ms Funnell), the Diabetes Outpatient Education Program (Dr Butler), and the Department of Postgraduate Medicine/Health Professions Education (Dr Anderson), University of Michigan, Ann Arbor. Michigan, and Humedico, Inc (Ms Feste), Eden Prairie, Minnesota.

Support for the development, dissemination, and this evaluation of Empowerment: A Personal Path to Self-Care was provided by Miles, Inc, Diagnostics Division.

This study was supported in part by a grant from the National Institute of Diabetes, Digestive, and Kidney Diseases of the National Institutes of Health, Grant No. 5P60-DK20572.

Correspondence to Marilynn S. Amold, MS, RD, CDE, Michigan Diabetes Research and Training Center, University of Michigan, C333 Med Inn, Box 0832, 1500 East Medical Center Drive, Ann Arbor, MI 48109.

Reprint requests to The Diabetes Educator, 367 West Chicago Avenue, Chicago, IL 60610. 
benefits (see Table). The purpose of this paper is to describe key ingredients for planning and implementing a successful patient empowerment program.

\section{Planning for Teaching the \\ Patient Empowerment Course}

Educator Philosophy The empowerment philosophy, effective problem solving, and accepting responsibility for one's own life are conveyed as much by the group leader's attitude as by the curriculum itself. Because acceptance of this philosophy is essential to facilitate the course, educators need to answer the following questions to determine if the empowerment philosophy is consistent with their own philosophy:

- Do you believe that diabetes and diabetes care involves almost every aspect of a patient's life?

- Are you comfortable with expressions of feelings? Expressions of anger, sadness, fear, and frustration often emerge during this program, and the expression of those emotions can help reduce their intensity and power to cause suffering.

- Are you comfortable encouraging patients to solve their own problems? We believe unsolicited advice from others often is a barrier to personal discovery and growth.

- Do you respect the rights of patients to make their own choices, even if you disagree with those choices? The empowerment philosophy assumes that individuals care about themselves and will strive to make decisions they perceive to be in their own self-interest. When patients make decisions that are internally motivated, they will have greater and longer-lasting energy for follow-through than if their decisions are externally motivated (eg, to please the provider).

Facilitator Training In order to offer the empowerment program, diabetes educators are required to attend a l-day training session in which the curriculum content and process are introduced with a combination of presentations, individual exercises, and small-group discussions. A leader's guide is provided during training and s̀ets of patient handouts are available upon request after completing the workshop. Facilitator training is available to chapters of the American Association of Diabetes Educators (AADE) and other groups of diabetes educators.

Team Teaching Team teaching the empowerment program provides many advantages, although it is not essential to use this teaching approach. Team planning helped us generate ideas and insights. Alternating the leadership role also reduced the amount of time and effort required to offer the program and provided participants with different perspectives. The backup facilitator greeted participants as they arrived, followed up on individual requests for information or assistance, and made sure that latecomers had the information/materials needed for class while the lead facilitator conducted the session.

The class was divided into two smaller groups for discussions. Having one leader facilitate each group and guide the discussions encouraged all group members to participate and provided an opportunity for individuals to express themselves, resulting in many valuable contributions to the group

\section{Benefits Identified By Participants*}

\section{Acknowledged denial}

- My sugar level was 453 and had been there for I don't know how long because I was not diabetic.

- I stopped keeping secrets.

- I came to the meetings thinking I'm just going to learn another diet here. I found out this [diabetes] could kill me.

\section{Became more assertive}

- The program has helped me learn how to say no.

- I have asked my doctor more questions.

- I've stopped being everybody's cheerleader.

\section{Improved stress management}

- I am more conscious of and [in] control of how my attitude affects stress levels and ability to cope with life in general.

- I've learned to relax, prioritize, not fret the small stuff.

- I've changed my position within the corporation where I work and my stress level is much, much reduced.

\section{Changed attitude}

- My outlook on life with diabetes is better as a whole. I don't feel sorry for myself quite so of ten.

- I don't have to take care of everybody anymore.

- It has been good for me to know I'm not alone in this.

\section{Gained problem-solving skills}

- It has made me more aware of problems and how to solve them.

- I think it was so helpful . . . mainly the exchange of ideas, experiences, failures, how other people got past a problem.

\section{Improved productivity}

- Last year I missed over 40 days worth of work . . this year I missed $51 / 2$ days. The program has really made me strong.

- I had missed lots of work before the program, and this last year I missed maybe 4 or 5 days. I received a promotion. I'm very pleased with that.

*Patient quotes.

experience. Our ability to answer questions and correct misinformation was enhanced by involving educators with differing expertise (eg, nurse and dietitian). Clinical discussions were kept brief and continued outside of class time when needed. We found that having opportunities to reflect together on our class experiences contributed to our growth as individuals and as educators.

Program Orientation It is essential that potential participants clearly understand the nature of this program. They need to know what to expect and what is expected from them. Therefore, we held an orientation session during which the empowerment approach and an overview of course objectives and topics were presented. Attendees had the opportunity to participate in a sample exercise and listen to someone describe their experience with the empowerment program. Participant expectations and responsibilities were explained, and the importance of making a commitment to attendance and being willing to share experiences and ideas was stressed. We emphasized that although the course offers structure and tools, the real content and quality of the 
program depends on an individual's participation and commitment.

It is important for participants to join the program to meet their own needs and not to help others. No one was pressured to enroll. Such pressure would sabotage one of the course's primary goals, which is to nurture self-directed decision making. Two participants who reported complete satisfaction with their own life choices said they wanted to help others. However, their tendency to offer unsolicited advice was a barrier to other participants' exploration of issues and problem-solving.

Criteria for Participant Selection Recruitment for the empowerment program was directed toward those who had received basic diabetes education so that there was some common understanding of diabetes. The majority $(85 \%)$ had completed a diabetes education program. Two participants took a basic diabetes education and empowerment course simultaneously. They later acknowledged that this entailed a significant time commitment, but they felt that the two programs were complementary.

Group size was targeted at 15 subjects per group, but was expanded to 18 due to demand. This group size allowed everyone an opportunity to contribute, especially when the class was divided into two smaller groups. Based on our experience, the program would work with 10 to 20 people, but less than 10 would be too small and hinder discussion, particularly when there are absences.

Course participants were invited to bring a guest to class; $30 \%$ of the participants came with a guest, usually a spouse $(83 \%)$, although other family members or friends also attended. Most guests attended every session.

Guests were invited to participate in the course activities or to observe to the extent they chose. Because most of the issues and exercises addressed in class were applicable to people without diabetes, guests were given their own set of handouts. Guest participation ranged from fully engaged to detached (eg, reading a book during class). This varying level of participation was not perceived by the leaders as a barrier to group dynamics.

No limitations on age or duration of diabetes have been suggested by our experience. Although the majority of participants were older (mean age $=51$ years), had experience living with diabetes (mean duration $=11.5$ years), were female $(67 \%)$, and had non-insulin-dependent diabetes mellitus (NIDDM) (68\%), there was considerable diversity. Age ranged from 24 to 75 years and duration of diabetes ranged from 1 to 42 years. The majority (94\%) of participants were Caucasian and had some college $(77 \%)$. In addition to this study population, the curriculum was presented in a condensed format to an urban community audience that was comprised of $10 \%$ to $20 \%$ minorities. Benefit from or appreciation of the empowerment program did not appear to be related to demographic factors. One newly diagnosed person summarized the value of discussion within a diverse group: "I think exchanging all the ideas and listening to everybody helped me avoid a lot of the pitfalls that people start out with when they have this disease. I can't tell you how much I learned and was able to apply."
Class Format Educators are encouraged to adapt the program to the needs and characteristics of their target audience. The schedule used for this study was a 2-hour evening session that met weekly for 6 weeks. The format included a brief presentation by the educator, time for personal reflection, large and small group discussion, and planning for change. Worksheets were provided to help participants assess their current beliefs and behaviors and were completed individually either during the session or in preparation for each of the sessions. Any behavior-change efforts that patients made between sessions were viewed as experiments. Participants were taught that they can learn from the results of their efforts regardless of the outcome.

Theoretically, the empowerment philosophy is an appropriate approach for any group regardless of cultural heritage or literacy level. (However, this curriculum probably would not benefit young children or mentally impaired adults because some level of abstract thinking is required to complete the worksheets.) The approach respects diversity and a person's right to decide if and what they want to change. The curriculum is a tool for teaching self-change skills, but does not specify the specific changes to make. The curriculum materials may need to be adapted for particular groups (eg, lowering the reading level, translating into other languages, modifying drawings to represent different ethnic groups, and increasing type size for persons with low vision). Although our experience with minority populations is limited, this curriculum currently is being tested with an African American population to learn how to adapt it for diverse populations.

\section{Key Ingredients for Implementation}

Group leaders need to address the following issues to maximize program benefits. These issues are not unique to this curriculum, but awareness of and attention to them may be particularly important for meeting the empowerment program objectives.

1. Create a psychologically safe (accepting, uncritical) environment for personal reflection and sharing.

People can learn from talking about their own experiences and from listening to the experiences of others. People usually will express themselves honestly to the extent they believe that they are accepted and respected. The following suggestions can help create an environment in which patients can begin to evaluate for themselves what their goals are and what they are ready to do about achieving these goals:

- Avoid giving advice.

- Accept, acknowledge, and avoid attempts to change participants' feelings about or perception of their experience.

- Emphasize the confidentiality of group discussions.

- Share personal stories to illustrate points and model storytelling.

- Communicate acceptance of all comments (acceptance does not mean agreement) and support diversity of opinion. Note that it is important to clarify clinical misinformation.

2. Accept our role as educators and facilitators, not group therapists.

The subject of personal counseling was mentioned briefly in our study (several people acknowledged treatment for depression), and some individuals may have benefitted from 
individual or group therapy. However, it was not the objective of the course nor within our scope of professional practice to provide psychotherapy. Using the course material to help participants assess their personal beliefs and behaviors and plan for self-directed changes does not require training in psychotherapy. Each facilitator brings different life experiences and professional skills that enhance the patient empowerment curriculum. However, interpersonal communication skills, sensitivity, patience, warmth, openness, and respect for the inherent worth of each participant are essential educator traits for conducting this program.

\section{Balance the needs of verbal and reticent group members.}

To balance the needs of verbal and reticent group members, facilitators may need to intentionally encourage/allow quieter members to express themselves. Verbal expression can be instrumental in helping participants clarify their perspective. We found the following techniques successful in helping participants meet course objectives:

- Engage participants in conversation before or after class.

- Divide the class into smaller groups for discussion. Many people find smaller groups less intimidating; they do not have to talk as loudly to be heard or work as hard to get a chance to speak.

- Observe nonverbal signals. Sometimes a person's body language suggests that they have something to say.

- Ask each person to answer an open-ended question. Although we used this technique sparingly, it was always effective. For example, as an icebreaker on the first day of class participants were asked to introduce themselves and comment on why they came. As a means of closure on the last day, participants were asked to comment on their experience of having been in the class. These questions precipitated many in-depth responses that were powerful and important contributions.

- When necessary, set ground rules that require everyone to have an opportunity to speak before anyone may speak a second time on a given topic.

\section{Provide significant others with an opportunity to ex-} press their concerns.

Sometimes we observed tension between persons with diabetes and their spouse. This tension appeared to be related to the spouse's concern for their partner's health, but manifested itself as irritation, anger, worry, or efforts to persuade the person to better care for their diabetes. Suggesting that patients and their guests join separate small groups allowed for the unfettered expression of these tensions. This technique worked especially well in the session on giving and getting support.

\section{Guide discussion to stay focused on course objectives.}

The overall course objectives are to increase the participants' self-awareness, to practice using skills such as goal setting and getting support, and to plan and implement self-directed behavior changes. The role of the facilitator is different and often more challenging than teaching factual information about diabetes. The program exercises and worksheets are highly effective as springboards for reflection, personal assessment, and discussion. If the discussion is productive, there is no need to complete all of the exercises as you would during a typical diabetes self-management class. On the other hand, because people's life experiences provide the content, any topic may be relevant. Assessing the contribution of a particular discussion to course objectives is more difficult than deciding if a discussion clarifies the treatment of hypoglycemia. The leader is responsible for any necessary redirection.

\section{Summary}

Diabetes care should include opportunities for people to address the emotional, social, behavioral, spiritual, and psychological, as well as physical, challenges of living with their disease. The program Empowerment: A Personal Path to Self-Care addresses these issues.

The primary criteria for implementing a patient empowerment curriculum is that the course facilitator(s) share the empowerment philosophy. Conviction that patients have the ability to solve their own problems, a willingness to listen rather than advise, a deep respect for each person, and a commitment to personal empowerment are traits essential for successful facilitation of a patient empowerment program.

We believe that team teaching. having an orientation session, and providing patients with an opportunity to invite guests to classes contributed to the success of the program. There seems to be no reason to limit adult participation with respect to age, gender, diabetes duration, cultural background, or type of diabetes.

Leadership responsibilities for facilitating the development of psychosocial skills in a patient empowerment class are different than the responsibilities of teaching diabetes information in a self-management class. The primary role of the leader is to create an uncritical, accepting environment in which class members can safely explore their own feelings, tell their stories, and solve their problems. Sensitivity, patience, warmth, and respect are needed to create this environment. Professional training as a therapist is not necessary to use the curriculum effectively. More intentional efforts may be needed to help class members and guests who have difficulty expressing themselves. Because any topic can be relevant, attending to and redirecting conversation may be necessary to keep the discussion consistent with course goals.

This empowerment course offers benefits to both patients and facilitators. Patients receive a valuable and potentially critical supplement to basic diabetes self-management training. Facilitators benefit from observing how their efforts help participants discover the personal power to improve their own lives.

\section{References}

1. Funnell MM, Anderson RM, Arnold MS, et al. Empowerment: an idea whose time has come in diabetes education. Diabetes Educ 1990;17(1): 37-41.

2. Anderson RM, Funnell MM. Arnold MS. Beyond compliance and glucose control: educating for patient empowerment. In: Rifkin $H$, Colwell JA. Taylor S1, eds. Diabetes. Amsterdam, Netherlands: Elsevier Science Publishers, 1991:1285-89.

3. Funnell MM, Anderson RA, Arnold MS. Empowerment: a winning model for diabetes care. Practical Diabetol 1991:1(93):15-18.

4. Feste CC. A practical look at patient empowement [Commentary]. Diabetes Care 1992;15(7):922-25. 
5. Thorne SE, Robinson CA. Guarded alliance: health care relationships in chronic illness. Image: J Nurs Scholarship 1989;21(3):153-57.

6. Michigan Diabetes Research and Training Center. Goal-setting. In: Non-insulin-dependent diabetes: a curriculum for patients and health care professionals. Ann Arbor. Mich: Michigan Diabetes Research and Training Center, 1992.

7. Pryor B, Mengel MC. Communication strategies for improving diabetics' self-care. J Commun 1987;37(4):24-35.
8. Anderson RM, Funnell MM, Barr PA, Dedrick RF, Davis WK. Learning to empower patients. Results of professional education for diabetes educators. Diabetes Care 1992:14:584-90.

9. Feste CC: Empowerment: facilitating a path to personal self-care. Elkhart, Ind: Miles Diagnostic Division, 1991.

10. Anderson RM, Funnell MM, Butler P, Arnold MS, Fitzgerald J, Feste CC. Patient empowerment: results of a randomized controlled trial. Diabetes Care 1995:18(7). 